Vitaly K. Avilov ${ }^{1,3 *}$, Dmitry G. Ivanov ${ }^{1,3}$, Konstantin K. Avilov' ${ }^{2}$, Ivan P. Kotlov ${ }^{1,3}$, Nguyen Van Thinh ${ }^{3}$, Do Phong Luu ${ }^{3}$ and Julia A. Kurbatova ${ }^{1}$

${ }^{1}$ A.N. Severtsov Institute of Ecology and Evolution RAS, Moscow, Russia

${ }^{2}$ Marchuk Institute for Numerical Mathematics RAS, Moscow, Russia

${ }^{3}$ Joint Russian-Vietnamese tropical research center, Soutern branch, Ho Chi Minh

city, Vietnam

* Corresponding author: vit.avilov@gmail.com

\title{
HOT SPOTS OF SOIL RESPIRATION IN A SEASONALLY DRY TROPICAL FOREST IN SOUTHERN VIETNAM: A BRIEF STUDY OF SPATIAL DISTRIBUTION
}

\begin{abstract}
Many studies report asymmetrical spatial distribution of soil respiration caused by presence of areas with significantly higher emission rates (so-called hot spots). For seasonally dry tropical forest soil respiration was measured on 1 ha plot with 20m, $5 \mathrm{~m}$ and $1 \mathrm{~m}$ scale in the first half of dry season. 457 measurements made in 9 series at 54 sampling points. The results suggest that lognormal spatial distribution model appears to be much more supported rather than the normal one. A statistical method proposed for estimation the mean value and its confidence interval of lognormally distributed data. The mean emission rate $\mathrm{E}\left(R_{\mathrm{s}}\right)$ for the lognormal distribution amounted to $4.28 \mu \mathrm{mol} \mathrm{m} \mathrm{m}^{-2}$ $\mathrm{s}^{-1}$, the $95 \%$ confidence interval is 3.93 to $4.76 \mu \mathrm{mol} \mathrm{m} \mathrm{m}^{-2} \mathrm{~s}^{-1}$. However, the standard sample mean can be used as an estimator of the mean of lognormally distributed values of soil respiration if their coefficient of variance remains approximately the same as in our study $(\mathrm{CV}=0.35)$. Based on the data obtained and literature sources, recommendations are given on the number of sampling points for estimating the spatial average value with a given accuracy
\end{abstract}

KEY WORDS: soil respiration, carbon emission, hot spots, tropical forest, spatial variability, sample size

CITATION: Vitaly K. Avilov, Dmitry G. Ivanov, Konstantin K. Avilov, Ivan P. Kotlov, Nguyen Van Thinh, Do Phong Luu and Julia A. Kurbatova (2019) Hot spots of soil respiration in a seasonally dry tropical forest in southern Vietnam: a brief study of spatial distribution. Geography, Environment, Sustainability,

Vol.12, No 2, p. 173-182

DOI-10.24057/2071-9388-2018-87

INTRODUCTION

Tropical forests contain about $40 \%$ of the global vegetation carbon and are responsible for about $50 \%$ of terrestrial gross prima- ry production. Owing to their large C stocks and budgets, tropical forests can affect the global C balance, and hence potentially play an important role in climate change, despite only covering $12 \%$ of the total land 
surface (FAO 2001). Seasonal forests represent $43 \%$ of the total tropical forest area, which is comparable with that of tropical rainforests.

In tropical forest ecosystems, the eddy covariance method has improved our understanding of ecosystem carbon cycle processes (e.g. Yamamoto et al. 2005; Kumagai et al. 2006; Kosugi et al. 2008). However, this method can provide unreliable nocturnal $\mathrm{CO}_{2}$ fluxes under low wind speed conditions (Baldocchi 2003), which can be used as a proxy for ecosystem respiration; thus, alternative chamber methods for measuring respiration are still important for understanding the processes of carbon flow in relation to climate change (Kume at al. 2013).

Soil $\mathrm{CO}_{2}$ efflux (syn. soil respiration, $\mathrm{R}_{\mathrm{s}}$ ) is the sum of multiple processes in rhizosphere, bacteria and fungi, soil fauna, litter decomposing organisms respiration and other, and many factors affect each of these components. Although soil temperature and soil water content are considered as primary drivers of soil respiration, coincidence of secondary factors (such as root biomass, organic carbon content, insect nests (Lopes de Gerenyu et al. 2015)) can cause emission values considerably exceeding surrounding background, which makes soil respiration a process of high spatial and temporal variability. Areas with significantly higher emission rates are generally recognized as hot spots (McClain et al. 2003). Sever- al problems may appear when estimating spatial average value of soil respiration. Due to insufficient sampling, the hot spots can be not taken into account at all, or they could be treated as a measurement artifact and discarded.

Soil respiration hot spots can be considered as ecosystem control points - points (spatial or temporal) where the exchange rate is of sufficient magnitude or ubiquity to affect dynamics of the ecosystem (Bernhardt 2017). With this approach, investigating the properties of soil respiraton hotspots can lead to a better understanding of ecosystem processes.

Aim of this study was evaluation of spatial variability of soil $\mathrm{CO}_{2}$ efflux in seasonally dry tropical forest, describing magnitude, size and temporal behavior of hotspots and estimation of optimum amount of sampling for further studies.

\section{STUDY AREA}

The study has been carried out in semi-deciduous tropical forest of Cat Tien national park (a part of the Dong Nai Biosphere Reserve) located in Dong Nai province, Vietnam (Fig. 1). The mean annual temperature, measured on Dong Xoai meteorological station approx. $57 \mathrm{~km}$ WNW from the study site in 1981 - 2010 was $26.4{ }^{\circ} \mathrm{C}$ with annual variation of monthly averages within $4^{\circ} \mathrm{C}$, mean annual rainfall amounts to $2518 \mathrm{~mm}$ (Deshcherevskaya

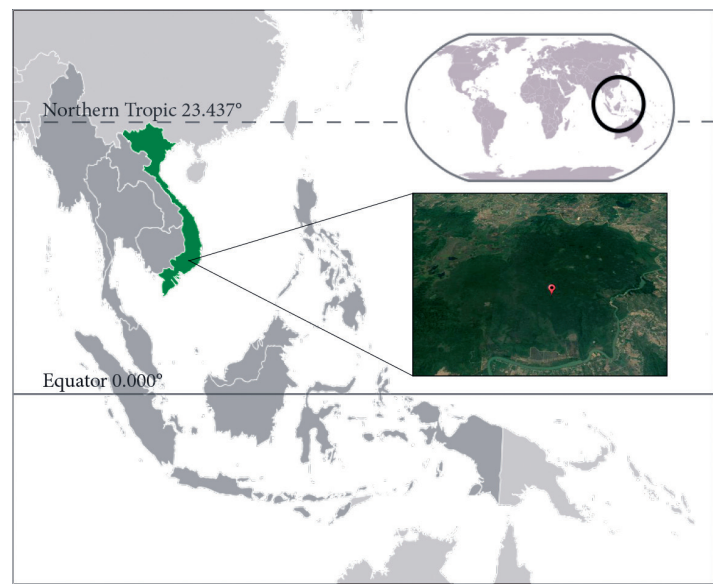

Fig. 1. Location of the study site (satellite image credits: CNES/Airbus 2018, DigitalGlobe 2018) 
et al. 2013). Climate of the region described as tropical monsoon (Am) by Köppen climate classification, which characterized by pronounced dry season, which lasts from December to March: mean total rainfall for this period makes only $5 \%$ of the annual amount. The forest dominant deciduous tree species are Lagestroemia caluculata, Tetrameles nudiflora, Hopea odorata, Ficus spp (Kuznetsov and Kuznrtsova 2011). Forest understory is abundant and evergreen, with minor grass cover. Soil of the study site is very dark brown (7.5YR 2.5/2 by Munsell color system) andisol with negligible color variation among study area. Organic carbon content in upper layer $(0-20 \mathrm{~cm})$ is $5.34 \%$, nitrogen content is $0.44 \%, \mathrm{pH}$ is 5.56 (Okolelova et al. 2014).

\section{MATERIALS AND METHODS}

\section{Sampling design}

A measurement site of 1 ha $(100 \times 100 \mathrm{~m})$ was established in 50 meters south from NCT flux tower (Kurbatova et al. 2013; NCT - AsiaFlux. [Online]) with a zero point (SW corner) at $11.440309^{\circ} \mathrm{N}, 107.400072^{\circ} \mathrm{E}$. The measurement points were placed on 3 different scales (Fig. 2): in the center of each $20 \times 20 \mathrm{~m}$ subplot $(n=25)$, then one random subplot was partitioned with $5 \times 5 \mathrm{~m}$ grid and sampling points were placed on the intersections of the grid $(n=25)$, the final scale was a small transect of 4 sampling points, placed with $1 \mathrm{~m}$ interval between two points of $5 \times 5 \mathrm{~m}$ scale $(n=6)$.
The measurements of soil respiration were repeated in 9 series with 6-8 days interval during December 2017 to February 2018. Each of the series has been measured in two days: on first day each of 25 points of the $100 \times 100 \mathrm{~m}$ plot has been measured and rest of the points measured the next day. The measurements of each day were taken between 9 am and 12 pm, one time per measuring point. At each sampling point a PVC collar of $250 \mathrm{~mm}$ diameter was installed with depth of about 3-5 cm below ground and height of $5 \mathrm{~cm}$ above, tree litter was not removed from the collars. First measurements were taken 10 days after the collars installation. Soil respiration was measured with non-steady state closed loop chamber method using custom-made respirometer based on LI-820 infrared gas analyzer (LI-COR inc., USA). The measuring chamber (Fig. 3) was of hemispherical shape $2.8 \mathrm{I}$ in volume. Air intake was mounted at the top of the hemisphere, and the air return flow was distributed around the base perimeter, which made it possible to avoid the use of a fan and the consequent excessive turbulence inside the chamber. Air-tight connection to the collar was realized using a thin rubber sealing ring. $\mathrm{CO}_{2}$ concentration values were logged with 1 Hz rate during each 120 seconds-long measurement.

Air temperature inside the measuring chamber was registered for every $\mathrm{CO}_{2}$ efflux measurement to estimate molar volume. Soil temperature and volumetric water content were measured along with $\mathrm{CO}_{2}$

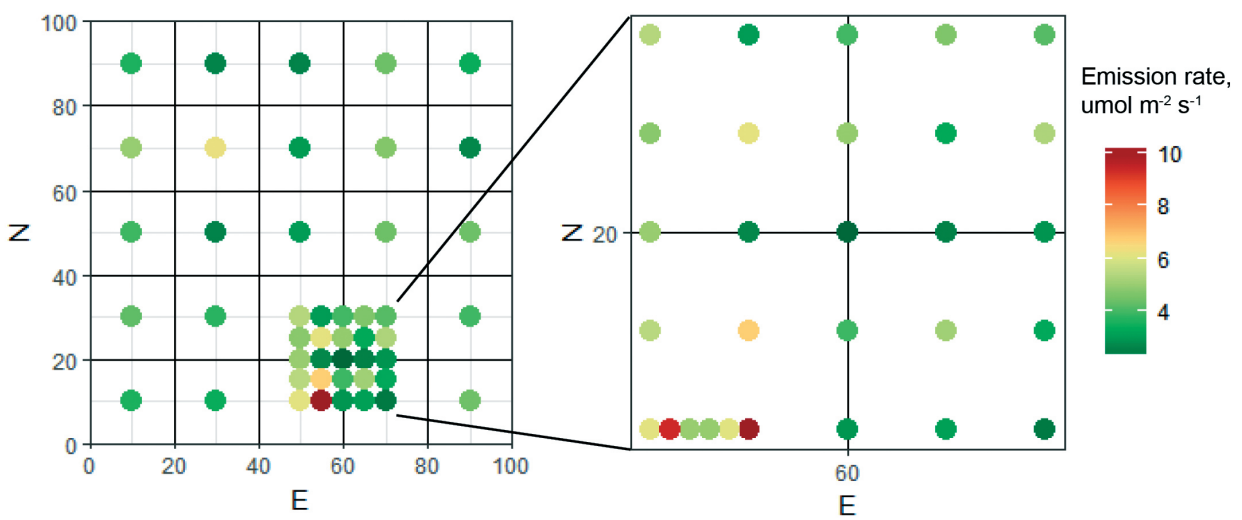

Fig. 2. Sampling design and time-averaged values of soil $\mathrm{CO}_{2}$ emission, $\mu \mathrm{mol} \mathrm{m}^{-2} \mathrm{~s}^{-1}$ (shown in color gradient). The numbers on axes represent distances to North and East from a zero point in meters 
efflux measurement in close proximity to the chamber. Soil temperature was measured at 2-5 cm depth using Checktemp-1 digital thermometer (Hanna instruments, USA). Soil volumetric water content was measured using electrical conductivity meter 5TE (Decagon Devices, Inc., USA). Due to the sensor failure, soil water content was measured only during first 4 series.

The method for calculation of $\mathrm{CO}_{2}$ efflux rate was similar to one used in commercial soil gas flux system LI-8100A (LI-COR inc., USA). $\mathrm{CO}_{2}$ concentration values from a first few seconds of a measurement were discarded due to disturbances caused by installation of the chamber. However, $\mathrm{CO}_{2}$ growth rate was estimated at the moment of chamber installation by approximation of good data with a gradient diffusion equation (Healy et al. 1996) using TableCurve2D software:

Where $C^{\prime}(t)$ is the instantaneous chamber

$$
C^{\prime}=C_{x}^{\prime}+\left(C_{0}^{\prime}{ }_{0}-C^{\prime}{ }_{x}\right) * e^{-\left(a^{*}\left(t-t_{0}\right)\right)}
$$

$\mathrm{CO}_{2}$ mole fraction, $\mathrm{CO}^{\prime}$ is the value of $C^{\prime}(t)$ when the chamber installed, and $C x^{\prime}$ is a parameter that defines the asymptote, all in $\mu \mathrm{mol} \mathrm{CO}_{2} / \mathrm{mol}$ air (ppm); a is a parameter that defines the curvature of the fit $\left(\mathrm{s}^{-1}\right)$. The $C x^{\prime}, a$ and $t_{0}$ parameters yielded by the regression were used to estimate $\mathrm{CO}_{2}$ concentration growth rate at the moment $t=t_{0}$ : Then $\mathrm{CO}_{2}$ efflux rate was calculated:

$$
\left.\frac{d C^{\prime}}{d t}\right|_{t=t_{0}}=a\left(C_{x}^{\prime}-C_{0}^{\prime}\right)
$$

Where $R_{\mathrm{s}}$ is soil respiration rate $(\mu \mathrm{mol} *$

$$
R_{s}=\left.\frac{d C^{\prime}}{d t}\right|_{t=t_{0}} * \frac{V_{c h}}{V_{m}} * \frac{1}{S_{c h}}
$$

$\left.\mathrm{m}^{-2} * \mathrm{~s}^{-1}\right)$, Vch is the volume of measuring chamber $\left(\mathrm{m}^{3}\right)$, Sch is the area covered with the chamber $\left(\mathrm{m}^{2}\right)$ and $\mathrm{Vm}$ is the molar volume for temperature measured inside the chamber $\left(\mathrm{m}^{3}\right)$.

\section{Statistical methods}

To make distribution of $R_{s}$ values from each measurement series comparable, the temporal trend was removed: we calculated the median value in each trial $\left(M_{i}, i=1, \ldots, 9\right)$, and the median of all values in the dataset $\left(M_{\text {all }}\right)$. Then, for each trial $(i=1, \ldots, 9)$ the detrended data were calculated as

$$
\widetilde{R}_{s}=R_{s}-M_{i}+M_{\text {all }}
$$

Hot spots were defined as outliers by Tukey's criteria (Tukey 1977) as it was done by other authors for defining geochemical phenomena (Kessel et al. 1993; Ohashi 2007). A sampling point was defined as a hot spot in the given measurement series when: $R>Q_{3}+1.5^{*} I Q R$, where $Q_{1}$ and $Q_{3}$ are $25^{\text {th }}$ and $75^{\text {th }}$ percentiles and $I Q R=Q_{3}-Q_{1}$ is the interquartile range of the deterended dataset.

The spatial dependence was analyzed by applying gammavariance technique (Bachmaier et al. 2011; Cressie 1993) with variogram function in "gstat" R package v.1.1-6 (Pebesma 2004).

Four normality tests were used (Lilliefors test, Anderson-Darling test, Kolmogorov-Smirnov test, and Jarque-Bera test) on both the original data and log-transformed data (testing for lognormal distribution).

Assuming that the time-averaged $\mathrm{CO}_{2}$

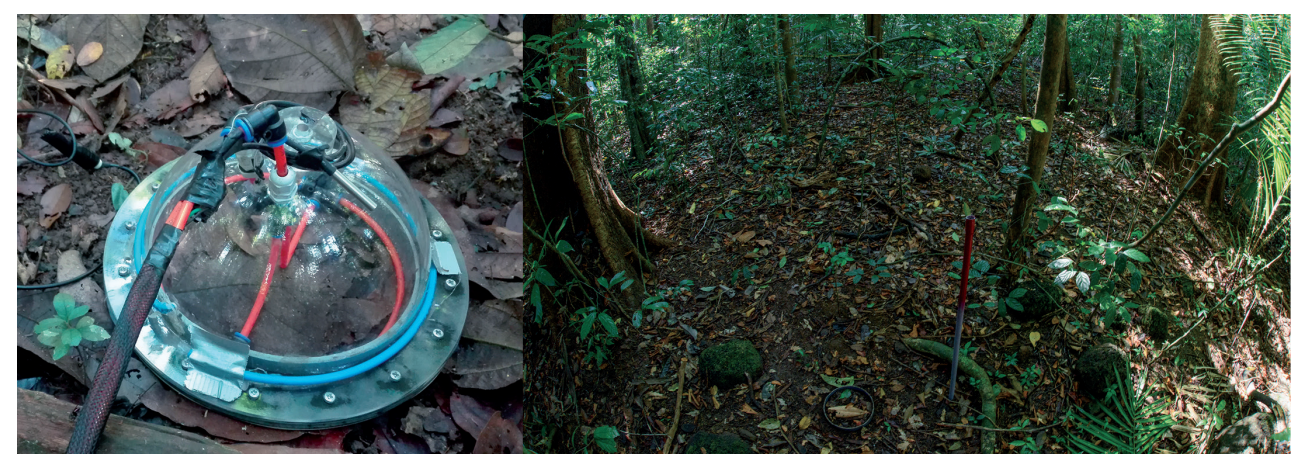

Fig. 3. Measuring chamber (left) and a collar at one of the sampling points (right) 
emission rates at different spatial locations are independent and follow lognormal distribution, the mean emission rate $\left(E\left(R_{s}\right)\right)$ was estimated using the method by Shen, Brown and Zhi (Shen et al. 2006):

where $X_{i}=\log R s_{i}$

$$
E\left(R_{S}\right)=\exp \left(\bar{X}+\frac{(n-1) S^{2}}{2(n+4)(n-1)+3 S^{2}}\right)
$$

is log-transformed data,

is the sample mean of $X$,

$$
\bar{X}=\sum_{i=1}^{n} X_{i} / n
$$

is the sample sum of squared deviations of

$$
S^{2}=\sum_{i=1}^{n}\left(X_{i}-\bar{X}\right)^{2}
$$

$X$, and $n$ is the size of the sample. The bootstrap confidence interval $(\mathrm{Cl})$ for $E\left(R_{s}\right)$ was generated with $10^{5}$ simulated samples.

To estimate the number of test sites required to measure the mean $\mathrm{CO}_{2}$ emission rate with given precision, we studied the properties of the bootstrap Cl by Shen et al. (2006).

If $R_{s}$ is a lognormally distributed random variable, $X=\log R_{s}$ is normally distributed with mean $\mu$ and standard deviation (SD) $\sigma$. The dimensionless parameter $\sigma$ is related to the coefficient of variation of $R_{S}$ :

where $C V=S D\left(R_{s}\right) / E\left(R_{s}\right)$ is the coefficient of

$$
\sigma=\sqrt{\log \left(C V^{2}+1\right)}
$$

variation of $Z$.

From Cl formulas in (Shen et.al. 2006) it can be shown that the relative width of the $\mathrm{Cl}$ $\left[\mathrm{C}_{1}, \mathrm{C}_{2}\right]$ for $\mathrm{E}\left(R_{\mathrm{s}}\right)$

is a function of $\sigma$ and $n$ only. At the same

$$
R W C I=\frac{c_{2}-c_{1}}{E\left(R_{S}\right)}
$$

time, RWCI may be considered as a measure of relative precision of estimation of $\mathrm{E}\left(R_{s}\right)$. Thus, if and target $R W C l$ are given, it is possible to estimate the required sample size $n$.

\section{RESULTS AND DISCUSSION}

The natural distribution of detrended soil respiration values displayed an asymmetrical distribution with the tail of higher values (Fig. 4). The obtained normality tests' $p$-values for time-averaged data are $0.1859,0.0046,0.6126,<0.001$ for the original data and $>0.5,0.5029,0.9345,>0.5$ for the log-transformed data ( $L, A D, K S$, and JB tests respectively). Although only two tests reject normality of the original data at 5\% significance level, lognormality of the data appears to be much more supported.

The mean emission rate $E\left(R_{s}\right)$ for the lognormal distribution amounted to $4.28 \mu \mathrm{mol}$ $\mathrm{m}-2 \mathrm{~s}-1$, the $95 \%$ confidence interval is 3.93 to $4.76 \mu \mathrm{mol} \mathrm{m} \mathrm{m}^{-2} \mathrm{~s}^{-1}$. The relative width of the confidence interval (RWCI) is 0.195. The median rate amounted to $3.95 \mathrm{\mu mol} \mathrm{m}^{-2} \mathrm{~s}^{-1}$ which is $12 \%$ lower than estimated mean value. The standard sample average, which suggests normal distribution, amounted to $4.31 \mu \mathrm{mol}$ m-2 s-1, with confidence interval in $3.88-4.74 \mu \mathrm{mol}$ m-2 s-1 and RWCl of 0.20 , which is quite close to the results of lognormal distribution Thus, we may state that the standard sample mean can be used as an estimator of the mean of lognormally distributed values of soil respiration if their coefficient of variance remains approximately the same as in our study $(C V=0.35)$. However, in the case of much more expressed hotspots (i.g. as described for methane emissions, denitrification and other processes by Bernhardt (2017)), these estimates may differ significantly, and the use of our proposed method for estimating the average of the lognormal distribution will be reasonable.

The results of the individual measurement series are shown in Table A.1.

There was no significant overall trend in $R_{s}$ during the measurement campaign (slope $<0.03 \mu \mathrm{mol} \mathrm{m} \mathrm{m}^{-2} \mathrm{~s}^{-1}$ per day). Some hot spots were stable in time, while some appeared only once or twice, and some points oppositely reacted to the same change in conditions. Our data shown no statistical dependence of soil respiration on temperature (linear model $R^{2}<0.006, p$-value: 0.11) 

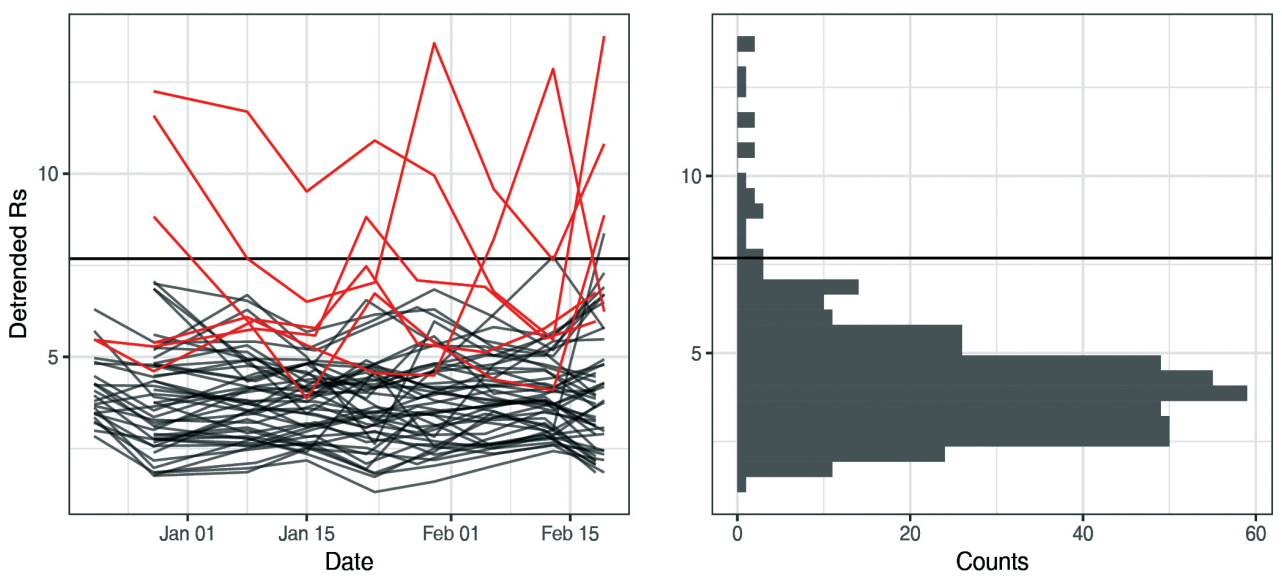

Fig. 4. Left plot: variation of soil respiration rate on individual sampling points along the measurement campaign. Trend of spatial median fluctuation is removed (median values of each measurement series are corrected to the common median value). The black lines represent sampling points with no hot moments detected. Right plot: frequency distributon of detrended soil respiration values $(n=486)$. The horizontal black line on both plots shows the Tukey`s outlier criteria

and soil moisture (linear model $R^{2}>0.03$, p-value: 0.04), and we suggest that none of these factors determine abnormally high emission values. Thus, it can be argued that observed soil respiration hotspots are of a different nature, and each detected hotspot may be due to different factors and react differently to the same change in environmental conditions.

The spatial dependence analysis didn't show any systematic behavior described by theoretical models (linear, spherical, exponential, Gaussian, and power law). This can serve as the evidence of heterogenous nature of time-averaged $\mathrm{CO}_{2}$ efflux values or a hypothesis that the scale of spatial variation of soil $\mathrm{CO}_{2}$ efflux at our site was smaller than double minimal distance between sampling points, i.e. less than 2 meters. Two-sample t-test showed statistically different mean values of two most expressed hotspots with any surrounded sampling point within 2 meter radius.

The time-averaged soil respiration values obtaineded at 54 sampling points produce standard deviation of log-transformed values $\sigma=0.3433$ (with corresponding 95\% confidence interval $C V(Z)=0.3537)$. In order to estimate the possible range of $\sigma$, we fetched data from four other studies of tropical forests in Southeast Asia (Ohashi
2007; Katayama 2009; Kosugi 2007; Adachi 2009) in the form of sample means and sample SDs (20 sets of data in total, with varying conditions and sample sizes). The data were used to calculate rough estimations of CVs (because sample means and sample SDs are very biased estimators of true means and SDs of lognormal distributions), and, in turn, to calculate rough estimations of . The minimal observed $\sigma$ was 0.2576 , the maximum one was 0.5847 , with a peak of frequency near to our $\sigma=0.3433$. So we decided to explore the range $\sigma \in$ $[0.15 ; 0.75]$.

The calculated RWCls for various and $n$ are shown in Fig. 5. Every value was calculated using 105 simulated samples in the bootstrapping procedure. The graphs may be used for estimating the required sample size if target RWCl is known and is estimated in a pilot study or assumed from literature data.

For $\sigma=0.35$, which can be considered as typical, some RCWI values were tabulated (Table 1):

These values clearly show that sampling design which includes 5-10 spatial probes may produce estimates very far from the true mean $\mathrm{CO}_{2}$ emission rates. 


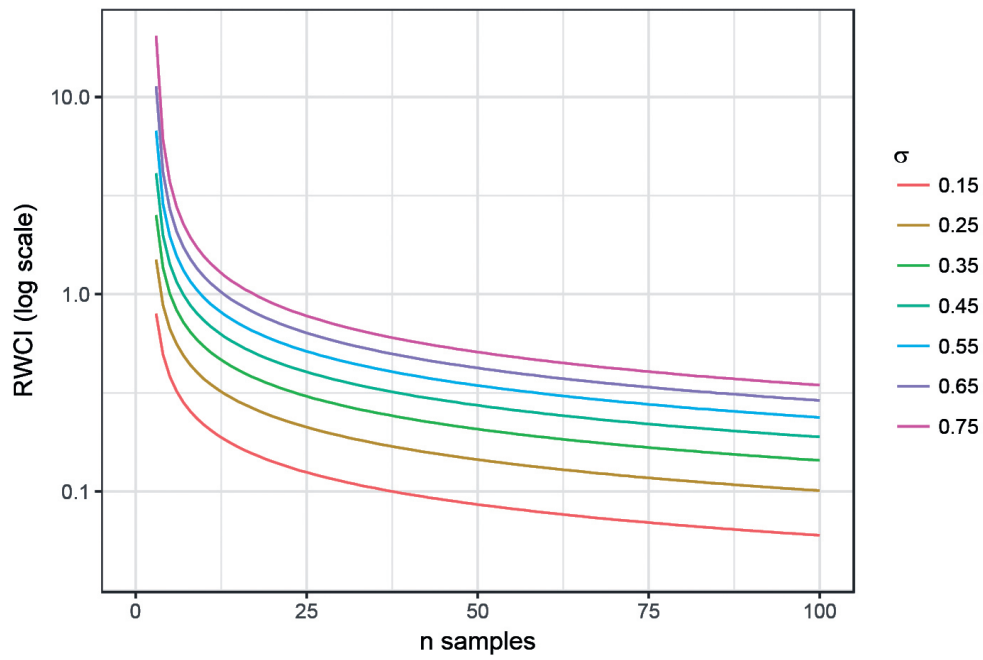

Fig. 5. Relative width of the $95 \%$ confidence interval for the mean of lognormally distributed variable $Z$ as a function of its $\sigma=S D(\log Z)$ parameter and sample size $n$

Table 1. Relative widths of $95 \%$ confidence intervals for $\sigma=0.35$. Lognormal distribution is assumed

\begin{tabular}{|c|c|c|c|c|c|c|c|c|c|}
\hline $\mathrm{n}$ & 3 & 5 & 10 & 20 & 30 & 40 & 50 & 60 & 70 \\
\hline $\mathrm{RWCI}_{\sigma=0.35}$ & 2.488 & 1.005 & 0.542 & 0.346 & 0.274 & 0.234 & 0.207 & 0.188 & 0.173 \\
\hline
\end{tabular}

\section{CONCLUSIONS}

Soil respiration rate in a seasonally dry tropical forest is highly variable in space, due to the small size of zones with significantly higher rates (hot spots). Spatial distribution of this parameter rejects normality tests, and lognormal distribution is much more supported by the statistical tests. However, we may state that the standard sample mean can be used as an estimator of the mean of lognormally distributed values of soil respiration if their coefficient of variance remains approximately the same as in our study $(C V=0.35)$.

Hotspots apparently have a heterogenous nature, some of them are more stable than another ones. The stable hot spots can be explained by higher root biomass and leaf area index $(\mathrm{LAI})$, the presence of decaying residues or areas of higher soil gas permeability. Rarely distributed short-term hot spots can be caused by insect activity. The detected hotspots apparently have a size of no more than 2 meters.
Assuming the lognormal nature of the distribution of soil respiration and the variability observed in our study and other literature sources, it may be proposed to make at least 20 spatially independent samples to obtain an estimate of the soil respiration with relative width of $95 \%$ confidence interval of no more than 0.35 of the estimated mean.

\section{ACKNOWLEDGEMENTS}

The study was funded by RFBR and Russian Geographical Society according to the research project № 17-05-41127 and partially was supported the Presidium of the Russian academy of sciences, Programs № 51 «Climate change: causes, risks, consequences, problems of adaptation and regulation» and № 41 "Biodiversity of natural systems and biological resources of Russia" 


\section{REFERENCES}

Adachi M., Ishida A., Bunyavejchewin S., Okuda T., \& Koizumi H. (2009). Spatial and temporal variation in soil respiration in a seasonally dry tropical forest, Thailand. Journal of Tropical Ecology, 25(05), 531. doi:10.1017/S026646740999006X.

AsiaFlux.net (2018). Asia Flux Official Website. [online] Available at: http://asiaflux.net/ index.php?page_id=86 [Accessed 31 Dec 2018].

Bachmaier M. \& Backes M. (2011). Variogram or semivariogram? Variance or semivariance? Allan variance or introducing a new term? Mathematical Geosciences, 43(6), 735-740.

Baldocchi DD. (2003). Assessing the eddy covariance technique for evaluating carbon dioxide exchange rates of ecosystems: past, present and future. Global Change Biology 9: 479-492.

Bernhardt E. S., Blaszczak J. R., Ficken C. D., Fork M. L., Kaiser K. E. \& Seybold, E. C. (2017). Control Points in Ecosystems: Moving Beyond the Hot Spot Hot Moment Concept. Ecosystems, 20(4), 665-682. doi:10.1007/s10021-016-0103-y.

Cressie N.A.C. (1993). Statistics for Spatial Data, Wiley.

Deshcherevskaya O.A., Avilov V.K., Dinh B.D., Tran C.H., \& Kurbatova J.A. (2013). Modern climate of the Cát Tiên National Park (Southern Vietnam): Climatological data for ecological studies. Izvestiya, Atmospheric and Oceanic Physics, 49(8), 819-838. doi:10.1134/ S0001433813080021.

FAO (Food and Agriculture Organization) (2001). Global Forest Resources Assessment 2000-Main Report. FAO Forestry Paper 140, Rome.

Katayama A., Kume T., Komatsu H., Ohashi M., Nakagawa M., Yamashita M. et al. (2009). Effect of forest structure on the spatial variation in soil respiration in a Bornean tropical rainforest. Agricultural and Forest Meteorology, 149(10), 1666-1673. doi:10.1016/j. agrformet.2009.05.007.

Kessel C., D. J. Pennock, and R. E. Farrell (1993). Seasonal variations in denitrification and nitrous oxide evolution at the landscape scale, Soil Sci. Soc. Am. J., 57, 988-995.

Kosugi Y., Takanashi S., Ohkubo S., Matsuo N., Tani M., Mitani T., Tsutsumi D., Abdul Rahim N. (2008). CO2 exchange of a tropical rainforest at Pasoh in Peninsular Malaysia. Agricultural and Forest Meteorology 148: 439-452.

Kosugi Y., Mitani T., Itoh M., Noguchi S., Tani M., Matsuo N. et al. (2007). Spatial and temporal variation in soil respiration in a Southeast Asian tropical rainforest. Agricultural and Forest Meteorology, 147(1-2), 35-47. doi:10.1016/j.agrformet.2007.06.005.

Kumagai T., Ichie T., Yoshimura M., Yamashita M., Kenzo T., Saitoh T.M., Ohashi M., Suzuki M., Koike T., Komatsu H. (2006). Modeling CO2 exchange over a Bornean tropical rain forest using measured vertical and horizontal variations in leaf-level physiological parameters and leaf area densities. Journal of Geophysical Research 111: D10107. DOI: 10.1029/2005JD006676. 
Kume T., Tanaka N., Yoshifuji N., \& Chatchai T. (2013). Soil respiration in response to year-toyear variations in rainfall in a tropical seasonal forest in northern Thailand. Ecohydrology, 6(1), 134-141. Available at: http://onlinelibrary.wiley.com/doi/10.1002/eco.1253/full.

Kuznetsov A.N., Kuznetsova S.P. (2011). Forest vegetation: species composition and stand structure. In: A.V. Tuonov, ed., Structure and functions of soil organisms in a tropical monsoon forest (Cat Tien national park, southern Vietnam). Moscow: KMK scientific press Itd., pp. 16-43 (in Russian with English summary).

Lopes de Gerenyu V.O., Anichkin A.E., Avilov V.K., Kuznetsov A.N., \& Kurganova I.N. (2015). Termites as a factor of spatial differentiation of $\mathrm{CO} 2$ fluxes from the soils of monsoon tropical forests in southern Vietnam. Eurasian Soil Science, 48(2). doi:10.1134/S1064229315020088.

McClain M. E., Boyer E. W., Dent C. L., Gergel S. E., Grimm N. B., Groffman P. M. et al. (2003). Biogeochemical hot spots and hot moments at the interface of terrestrial and aquatic ecosystems. Ecosystems, 6(4), 301-312.

Ohashi M., Kume T., Yamane S., \& Suzuki M. (2007). Hot spots of soil respiration in an Asian tropical rainforest. Geophysical research letters, 34(8), L08705. doi:10.1029/2007GL029587.

Okolelova A.A., Van T.N. \& Avilov V.C. (2014). Properties of basic types of soils in the Dong Nai biosphere reserve (south Vietnam). Belgogrod State University Scientific Bulletin: Natural Sciences, (27).

Pebesma E.J. (2004). Multivariable geostatistics in S: the gstat package. Computers $\backslash \&$ Geosciences, 30: 683-691.

Shen H., Brown L.D., \& Zhi H. (2006). Efficient estimation of log-normal means with application to pharmacokinetic data. Statistics in medicine, 25(17), 3023-3038.

Tukey J.W. (1977). Exploratory Data Analysis. Addison-Wesley. ISBN 978-0-201-07616-5. OCLC 3058187.

Yamamoto S., Saigusa N., Gamo M., Fujinuma Y., Inoue G., Hirano T. (2005). Findings through the AsiaFlux network and a view toward future. Journal of Geographical Society 15: 142148. 


\section{Appendix A}

Table A.1. Values of soil respiration rate, obtained in different series, $\mu \mathrm{mol} m-2 \mathrm{~s}-1$. SD is standard deviation of mean, $E(Z)$ is estimation of mean RS based on lognormal distribution. $\mathrm{Cl}$ low and $\mathrm{Cl}$ high are $95 \%$ confidence intervals of $\mathrm{E}(\mathrm{Z})$, JB-test is Jarque-

Bera test

ษ
๓

\begin{tabular}{|c|c|c|c|c|c|c|c|c|c|c|c|c|c|c|c|}
\hline Series & $\begin{array}{l}\text { Meas. } \\
\text { date }\end{array}$ & $\mathrm{n}$ & Min & Max & Median & Mean & SD & $E(Z)$ & $\begin{array}{c}\mathrm{Cl} \\
\text { low }\end{array}$ & $\begin{array}{c}\mathrm{Cl} \\
\text { high }\end{array}$ & RWCl & $\begin{array}{l}\text { JB-test } \\
\text { p-value } \\
\text { for Z }\end{array}$ & $\begin{array}{l}\text { JB-test } \\
\text { p-value } \\
\text { for } \\
\log (Z)\end{array}$ & $\begin{array}{c}\text { Mean } \\
\text { Ts, } \\
{ }^{\circ} \mathrm{C}\end{array}$ & $\begin{array}{c}\text { Mean } \\
\text { WWC, } \\
\mathrm{m}^{3} / \\
\mathrm{m}^{3}\end{array}$ \\
\hline 1 & $\begin{array}{c}2017 \\
-12-21\end{array}$ & 25 & 1.79 & 5.26 & 2.90 & 3.10 & 0.91 & 3.08 & 2.77 & 3.52 & 0.24 & 0.131 & 0.500 & 27.3 & 0.22 \\
\hline 2 & $\begin{array}{c}2017 \\
-12-28\end{array}$ & 54 & 2.24 & 12.73 & 4.42 & 4.77 & 2.14 & 4.72 & 4.28 & 5.35 & 0.23 & $\leq 0.001$ & 0.213 & 29.7 & 0.21 \\
\hline 3 & $\begin{array}{c}2018 \\
-01-08\end{array}$ & 54 & 2.04 & 11.88 & 4.13 & 4.41 & 1.68 & 4.38 & 4.02 & 4.87 & 0.20 & $\leq 0.001$ & 0.435 & 28.8 & 0.22 \\
\hline 4 & $\begin{array}{c}2018 \\
-01-15\end{array}$ & 54 & 1.85 & 9.19 & 3.62 & 3.67 & 1.28 & 3.65 & 3.36 & 4.04 & 0.18 & $\leq 0.001$ & 0.500 & 28.1 & 0.19 \\
\hline 5 & $\begin{array}{c}2018 \\
-01-23\end{array}$ & 54 & 2.20 & 11.79 & 4.83 & 5.00 & 1.81 & 4.97 & 4.57 & 5.52 & 0.19 & $\leq 0.001$ & 0.500 & 25.2 & $0.27^{*}$ \\
\hline 6 & $\begin{array}{c}2018 \\
-01-30\end{array}$ & 54 & 2.14 & 14.11 & 4.49 & 4.80 & 2.00 & 4.76 & 4.35 & 5.31 & 0.20 & $\leq 0.001$ & 0.048 & 25.2 & $0.25^{*}$ \\
\hline 7 & $\begin{array}{c}2018 \\
-02-06\end{array}$ & 54 & 1.49 & 9.05 & 3.41 & 3.67 & 1.49 & 3.65 & 3.31 & 4.12 & 0.22 & 0.002 & 0.500 & 22.2 & $0.18^{*}$ \\
\hline 8 & $\begin{array}{c}2018 \\
-02-13\end{array}$ & 54 & 1.55 & 11.98 & 3.06 & 3.41 & 1.68 & 3.36 & 3.04 & 3.82 & 0.23 & $\leq 0.001$ & 0.043 & 22.5 & $0.17^{*}$ \\
\hline 9 & $\begin{array}{l}2018- \\
02-19\end{array}$ & 54 & 2.42 & 14.34 & 4.53 & 5.10 & 2.35 & 5.05 & 4.55 & 5.75 & 0.24 & $\leq 0.001$ & 0.254 & 24.8 & $0.17^{*}$ \\
\hline
\end{tabular}

* the data fetched from NCT flux tower in 50-150 m away from the measured points 